\title{
Insights Into the Complexity of Craniofacial Development From a Cellular Perspective
}

\author{
Andrea P. Murillo-Rincón and Marketa Kaucka* \\ Max Planck Research Group Craniofacial Biology, Max Planck Institute for Evolutionary Biology, Plön, Germany
}

The head represents the most complex part of the body and a distinctive feature of the vertebrate body plan. This intricate structure is assembled during embryonic development in the four-dimensional process of morphogenesis. The head integrates components of the central and peripheral nervous system, sensory organs, muscles, joints, glands, and other specialized tissues in the framework of a complexly shaped skull. The anterior part of the head is referred to as the face, and a broad spectrum of facial shapes across vertebrate species enables different feeding strategies, communication styles, and diverse specialized functions. The face formation starts early during embryonic development and is an enormously complex, multi-step process regulated on a genomic, molecular, and cellular level. In this review, we will discuss recent discoveries that revealed new aspects of facial morphogenesis from the time of

Edited by:

Marcela Buchtova,

Czech Academy of Sciences, Czechia

Reviewed by:

Heather L. Szabo-Rogers,

University of Pittsburgh, United States

Paris Alexander Skourides,

University of Cyprus, Cyprus

*Correspondence:

Marketa Kaucka

kaucka@evolbio.mpg.de

Specialty section:

This article was submitted to

Cell Growth and Division,

a section of the journal

Frontiers in Cell and Developmental

Biology

Received: 23 October 2020 Accepted: 02 December 2020 Published: 18 December 2020

Citation:

Murillo-Rincón AP and Kaucka M (2020) Insights Into the Complexity of Craniofacial Development From

a Cellular Perspective.

Front. Cell Dev. Biol. 8:620735.

doi: 10.3389/fcell.2020.620735 the neural crest cell emergence till the formation of the chondrocranium, the primary design of the individual facial shape. We will focus on molecular mechanisms of cell fate specification, the role of individual and collective cell migration, the importance of dynamic and continuous cellular interactions, responses of cells and tissues to generated physical forces, and their morphogenetic outcomes. In the end, we will examine the spatiotemporal activity of signaling centers tightly regulating the release of signals inducing the formation of craniofacial skeletal elements. The existence of these centers and their regulation by enhancers represent one of the core morphogenetic mechanisms and might lay the foundations for intra- and inter-species facial variability.

Keywords: craniofacial development, neural crest, mesenchymal condensations, chondrocranium, facial shape, signaling centers, cellular behavior

\section{INTRODUCTION}

The shape of the face possesses species-specific features that give each vertebrate group its unique facial appearance. In some species such as humans, the otherwise conserved shaping mechanism is flexible enough to allow for shape fine-tuning, resulting in an impressive facial variability (Liu et al., 2012; Adhikari et al., 2016; Cole et al., 2016; Xiong et al., 2019). The shape of the face strongly depends on the geometry of underlying skeletal elements, adipose tissue, and muscles. While the postnatal facial skeleton in the majority of vertebrates is formed by bony elements, the embryonic face is built up entirely from cartilage and is represented by a complex structure called the chondrocranium. Most of the chondrocranium is substituted by the bone postnatally (McBratneyOwen et al., 2008; Kawasaki and Richtsmeier, 2017) and the functional and evolutionary meaning 
of chondrocranium is not fully understood. However, changes in chondrocranium morphology or morphometry remain even after its replacement by the bone (Kaucka et al., 2017), therefore, the formation of chondrocranium can be considered a key process in the acquisition of facial shape.

The chondrocranium formation is an intricate, multi-step process utilizing cells derived from all three germ layers and driven by, for instance, complex cell and tissue interactions, specific cellular behavior, or by a multitude of spatiotemporally active morphogens. In this review, we will summarize the advancements in our understanding of its developmental complexity. In the first part, we will focus on mechanisms driving the specification, delamination, and migration of cranial neural crest cells to their respective destinations, and their interactions with surrounding cells that result in sensory placode formation. Next, we will pinpoint to mutual interactions between different cell and tissue types, the cellular response to changing physical forces, and specific clonal behavior such as oriented cell division. In the end, we will expose the importance of the spatiotemporally defined activity of signaling centers driving the early craniofacial morphogenesis and discuss the possible genetic basis of facial variability.

\section{SPECIFICATION AND CELL FATE ACQUISITION OF THE NEURAL CREST CELL}

A milestone in the process of head formation is the emergence and migration of the neural crest cells (NCCs). The NCCs are transient multipotent progenitors arising from the borders of the closing neural tube (Figures 1IA,B; Basch et al., 2006; Pla and Monsoro-Burq, 2018; Prasad et al., 2020). Depending on the location of their origin along the anterioposterior axis of the neural tube and their post-migratory target destination, the cells are classified as cranial (or cephalic), cardiac, vagal (including enteric), trunk, and sacral NCCs (Rothstein et al., 2018). After the NCCs specification, the cells undergo epithelialto-mesenchymal transition (EMT), delaminate from the neural tube, and follow conserved stereotypical dorsolateral migratory streams (Figures 1IC,D; Minoux and Rijli, 2010; Theveneau and Mayor, 2012; Rothstein et al., 2018).

Interestingly, cranial and trunk NCCs utilize distinct migration strategies (Richardson et al., 2016). Trunk NCCs migrate as chains of single cells following the leader cells in the front of the streams. The leader cells manifest characteristic morphological properties that are observed already before the onset of migration and if ablated, the follower cells are unable to proceed ventrally pointing at the irreplaceable fixed role of the leader cell. Cranial NCCs move directionally as a whole and all the cells show similar migratory properties. All the cranial NCCs can serve as transient leaders and their ablation does not affect the migration of the following cells. Both cranial and trunk NCCs maintain continuous and dynamic cell-cell contact to keep migration and directionality (Richardson et al., 2016; Li et al., 2019). Analysis of the hierarchical clustering of NCCs in cyclostomes shed new light on the evolutionary origin of the cranial crest. The cranial subpopulation of lamprey NCCs showed transcriptional similarity to the gene signature of trunk NCCs in amniotes. These observations suggest that the NCCs underwent gradual acquisition of regulatory complexity during the evolution of vertebrates, leading to the existence of distinct NCC populations such as cranial and trunk, and likely affecting the vertebrate body plan (Martik et al., 2019).

The NCCs give rise to a broad spectrum of cell types such as neurons and glial cells of the peripheral nervous system, smooth muscles, endocrine cells, melanocytes, chondrocytes, odontoblasts, connective tissue, and bone (Bronner and LeDouarin, 2012; Baggiolini et al., 2015; Kaucka et al., 2016). In mouse, the analysis of the progenies (or clones) derived from genetically labeled single NCCs showed that each clone occupies a specific area in the forming head and has the potential to acquire diverse cell fates, therefore contributing to the formation of multiple structures in that particular location (Baggiolini et al., 2015; Kaucka et al., 2016). The impressive cell fate repertoire of the NCCs raised the question of how do NCCs generate and control their extraordinary multipotency and what are the molecular drivers of cell fate specification. Analysis of the pluripotency marker expression in cranial NCCs identified a neural crest stem cell niche located in the central-most portion of the dorsal neural tube (Lignell et al., 2017). Other NCC subpopulations positioned dorsolaterally to the stem cell niche expressed more canonical NCC markers or showed a typical migratory gene expression signature (Lignell et al., 2017). With increasing distance of NCCs from the central part of the neural tube, the effect of Wnt signaling coming from the neural tube decreases and results in the miRNA-mediated silencing of typical neural crest stem cell markers, leading to the loss of NCCs multipotency (Bhattacharya et al., 2018).

Epigenetic regulation is one of the further mechanisms controlling the cranial NCC plasticity, especially concerning their axial regional identity. The cranial NCCs maintain broad facial patterning competence and can contribute to different structures in the forming head. Cranial NCCs show similar chromatin accessibility patterns even though their transcriptional profile differs. The chromatin pattern is maintained until postmigratory stages when the cells commit to a specific fate in response to local cues (Minoux et al., 2017). In Xenopus, the activity of histone deacetylases (HDACs), enzymes regulating chromatin accessibility, was shown to be crucial in blastula cells for patterning the ectoderm and the establishment of NCCs, and in the NCCs to maintain their pluripotency (Rao and LaBonne, 2018).

The combination of the single-cell transcriptomics and bioinformatical analysis of branching trajectories of murine NCCs, revealed new aspects of NCC multipotency, EMT, and fate specification (La Manno et al., 2018; Soldatov et al., 2019). Recent findings disproved previous beliefs that these are abrupt events driven by the activation of a specific gene regulatory network or dependent on the expression of a master regulator gene. For instance, pre-migratory NCCs express both neural plate borderspecific genes and several neural tube markers (Lignell et al., 2017; Soldatov et al., 2019; Williams et al., 2019). The expression of NCC-specific markers gradually outweighs the expression of 

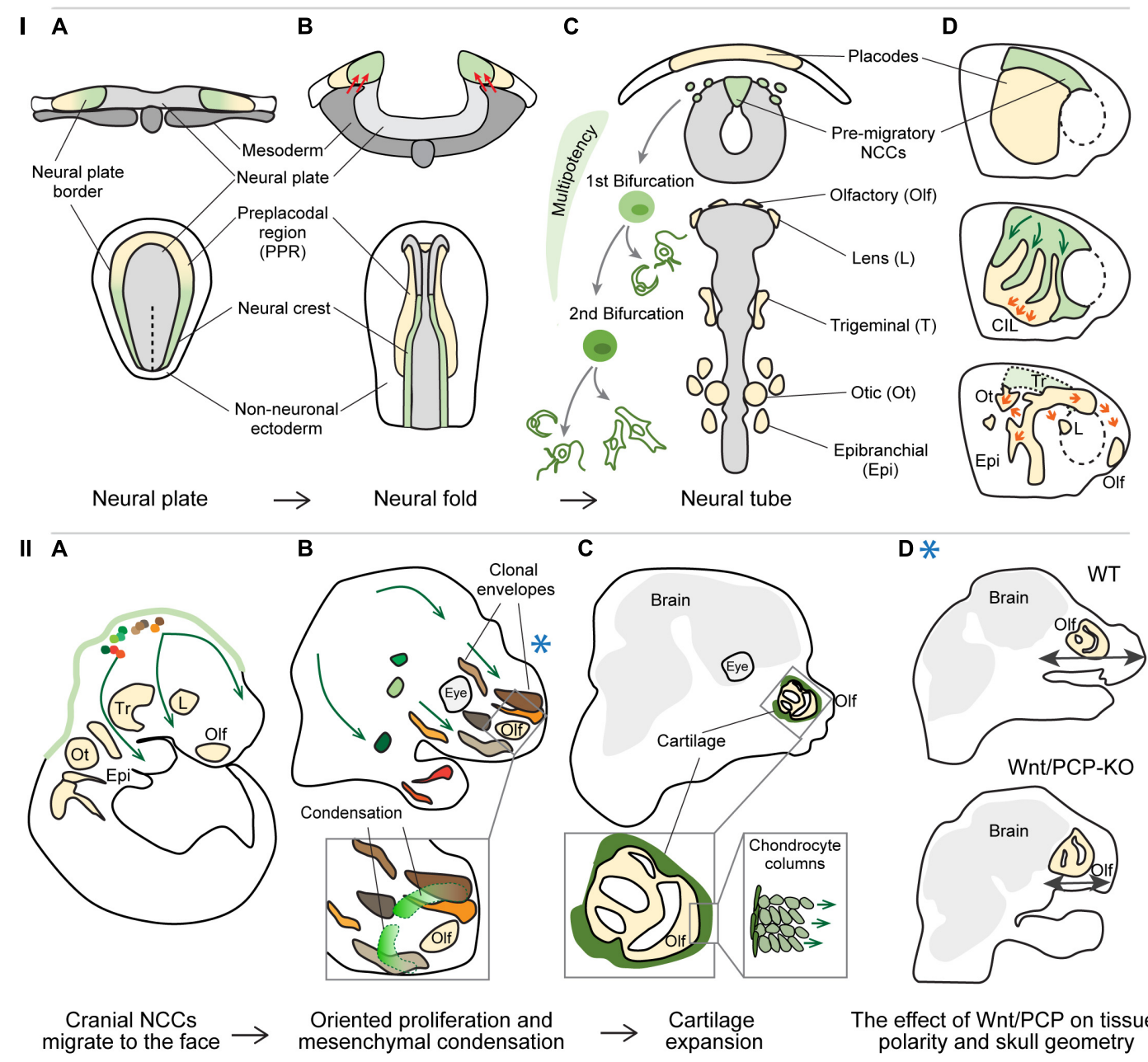

Oriented proliferation and

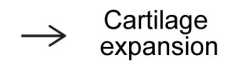

The effect of Wnt/PCP on tissue polarity and skull geometry

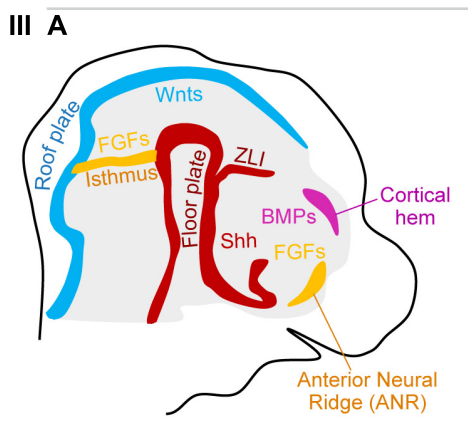

Signaling centers in the brain

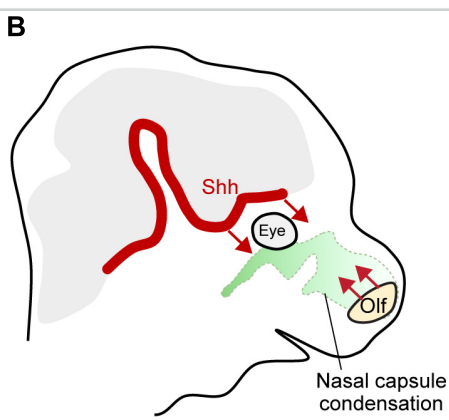

Induction of mesenchymal condensations
C

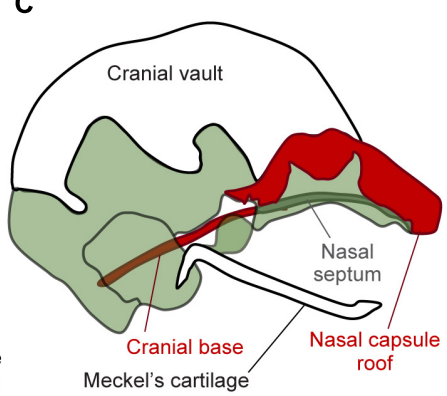

Chondrocranium Facial shape

FIGURE 1 | Panel I: Specification and cell fate acquisition of the neural crest cells (NCCs). (A) NCCs and placode progenitor cells are localized adjacent to each other at the neural plate border. (B) When neural folds are brought together, the stiffened mesoderm underlying the cranial NCCs (red arrows) triggers NCC EMT and initiate NCC migration. (C) The migrating NCCs undergo a gradual process of cell fate acquisition, during which the NCCs pass through two main bifurcation points. The first separation leads to the split of sensory and autonomic/mesenchymal fates, and the second separation leads to the emergence of autonomic and mesenchymal fates. Placode progenitors are split from the common PPR into individual placodes to give rise to different sensory organs or cranial ganglia. (D) NCCs migration streams and placode separation are a result of the interaction between NCCs and placode cells (middle): NCCs are attracted by placode cells (green arrows), after their direct contact placode cells are repolarized and move away from the NCCs (orange arrows), in a process called contact inhibition locomotion (CIL). Due to their active directed cell migration (orange arrows, below), the individual placode territories are established and NCCs had along their stereotypical migratory pathways. (A-C) Upper row transversal view, lower row: dorsal view; (D) lateral view. Panel II: Cellular behavior during early craniofacial morphogenesis.

(A) The cranial NCCs migrated into their respective destinations and proliferate generating facial ectomesenchyme. (B) The progeny of each cranial NCC occupies a 


\section{FIGURE 1 | Continued}

3D area referred to as the clonal envelope. NCCs undergo cell divisions in an oriented manner, the shapes of clonal envelopes reflect the anisotropic growth of the head. The mesenchymal condensations originate from the local ectomesenchyme and represent the blueprint for chondrocranium and future facial shape. Extensive cell proliferation in quite distant locations results in collective cell movement translocating the whole micro-domains. (C) The mesenchymal condensations start differentiating into cartilage, the chondrocytes undergo a series of polarized cell divisions resulting in surface expansion of the chondrocranium. (D) Polarized cell division of NCC-derived ectomesenchyme is controlled by Wnt/Planar cell polarity (PCP) pathway and its disruption leads to shorter and wider facial proportions. The Blue asterisk shows the relevant time point of the Wnt/PCP signaling effect - during the proliferation of ectomesenchyme (panel IIB). Panel III: Signaling centers establish facial geometry. (A) Signaling centers located in the developing brain instruct the formation of mesenchymal condensations from the ectomesenchyme. (B) Sonic hedgehog (Shh) from the floor plate induces the condensation leading to the formation of nasal septum as well some elements of the cranial base, while morphogenetic signals from the olfactory epithelium induce the formation of nasal capsule roof. (C) Removal of morphogenetic signals from distinct locations results in the absence or malformation of the respective cartilaginous structures.

neural tube-specific genes and the NCCs initiate delamination from the neural plate. The further existence of migrating NCCs is also defined by an extensive sequence of transcriptional events (Soldatov et al., 2019). Specifically, cell fate commitment is a result of co-activation of gene expression programs that would normally lead to mutually exclusive cell fates. Their competition is resolved after a bifurcation point, which is likely reached due to the effect of extrinsic signal such as WNT, BMP, Notch, or another signaling (Figure 1IC). Before the cell passes the bifurcation point, it can be perceived as bipotent progenitor. Interestingly, the first bifurcation point leads to division of progenitors into the sensory and autonomic neuronal/mesenchymal lineage, followed by the subsequent separation of autonomic neuronal progenitors from mesenchymal lineage (Figure 1IC; Soldatov et al., 2019), which is contrary to previous belief that each type of progenitor is directly derived from one common precursor.

\section{CELL AND TISSUE DYNAMICS IN EARLY CRANIOFACIAL MORPHOGENESIS}

Migration of single cells and large-scale collective cell movements represent important aspects of early facial morphogenesis. Such movements enable both mechanical and molecular interactions between cells and tissues, and their environment. One of the examples of such coordinated movement are the reciprocal interactions between the cranial NCCs and cranial placode cells. Cranial placode precursors arise at the anterior part of the neural plate border, and form a common pre-placodal region (PPR) characterized by the expression of the transcription factor Six 1 (Figure 1IA). The PPR is positioned in close proximity and laterally to the emerging neural crest cells (Sato et al., 2010; Saint-Jeannet and Moody, 2014; Riddiford and Schlosser, 2016; Roellig et al., 2017). The cranial placodes together with the cranial NCCs form specialized sensory organs in the vertebrate head (Figure 1IC; Bouchard et al., 2010; Ladher et al., 2010; Huang et al., 2011; Cvekl and Ashery-Padan, 2014). The separation of common PPR into individual placodes is closely related to NCCs migration (Figure 1ID). Delaminating NCCs are attracted by the chemokine Sdf1 (CXCL12) produced by the placode cells (Shellard and Mayor, 2019). Once the NCCs get in direct contact with placodal cells, a transient junction complex is formed and Wnt/PCP components together with $\mathrm{N}$-cadherin signaling trigger contact inhibition locomotion (CIL) (Theveneau et al., 2013). The cell protrusions and focal adhesions of placodal cells at the region of contact collapse, which leads to their repolarization and the directional migration away from the NCCs. Such "chase and run" behavior of NCCs following the Sdf1-producing placodal cells results in both the physical separation of future placodal regions and the establishment of the NCCs the migration streams (Figure 1ID; Szabó et al., 2019).

The cranial NCCs then follow stereotypical migratory streams and proliferate on their way to finally settle in various compartments of the head and produce ectomesenchyme (Figure 1IIA; Minoux and Rijli, 2010; Kaucka et al., 2016; Rothstein et al., 2018). While active and directional cell migration rather than cell proliferation drives the formation of the olfactory, lens, and otic placodes (Steventon et al., 2016; Breau et al., 2017), the ectomesenchyme expands by series of cell divisions and only very limited individual cell migration (Kaucka et al., 2016). A single NCC clone ultimately occupies a certain 3D space, referred to as a clonal envelop (Figure 1IIB). The shape and size of the clonal envelopes mirror the local directional cell behavior (the extent and the polarity of cell division), the level of mixing with other NCC clones, and reflect the anisotropic growth of different regions in the head. Each location is populated by several NCC-derived clones that extensively mix and jointly contribute to the formation of different structures in that area (Figure 1IIB). This might represent a compensation mechanism in the case that one or a few NCCs would be eliminated by, for instance, negative somatic mutations (Kaucka et al., 2016).

Functional experiments targeting different components of the Wnt/PCP signaling highlighted the importance of the ectomesenchyme polarity for the proper facial outgrowth in several developmental time-points. Overall, the rate of cell divisions in Wnt/PCP mutants does not appear to be affected, however, the impaired direction of daughter cell allocation during cell division results in a variety of pathologies, such as shorter and wider facial proportions, abnormal mesenchymal patterning during early palatogenesis or misoriented and misshaped chondrocytes affecting the facial morphometry (Figures 1IIC,D; Le Pabic et al., 2014; Brock et al., 2016; Kaucka et al., 2016). Oriented deposition of daughter cells also represents a core elongation mechanism driving the longitudinal growth of flat facial cartilage composing the mammalian chondrocranium (Figure 1IIC; Kaucka et al., 2017). Normal facial morphogenesis furthermore relies on coordinated collective cell movements, where the shift of large cell masses resembles the behavior of viscous fluids and allow large-scale cell rearrangements (David et al., 2014; Méhes and Vicsek, 2014; 
Kaucka et al., 2016; Tao et al., 2019). These crowd movements are driven by extensive cell proliferation in relatively remote regions positioned laterally or posteriorly to the respective area and allow the preservation of cellular arrangements of the pushed microdomains (Kaucka et al., 2016).

Furthermore, physical forces generated by morphogenetic events contribute to various aspects of head formation. Cranial mesoderm stiffening was shown to be necessary and even sufficient to induce NCCs EMT and migration in Xenopus (Figure 1IB; Barriga et al., 2018). The stiffness of the cranial mesoderm, underlying the cranial NCCs at the time of neurulation, is generated by the increase in cell density in the process of convergent extension. The NCCs use their integrin-vinculin-talin mechanosensory complex to perceive the mechanical changes in the environment, and respond by switching the expression of E-cadherin to $\mathrm{N}$-cadherin, gaining motility and responsiveness to chemotactic cues (Scarpa et al., 2015; Barriga et al., 2018). Mechanical forces also drive tooth morphogenesis (Mammoto et al., 2011; Panousopoulou and Green, 2016). The invagination of epithelial thickening into the mesenchyme is driven by the physical contraction of superficial layers of cells (i.e., suprabasal cells) (Panousopoulou and Green, 2016). The contraction is generated by the suprabasal cells intercalating and extending their cell shape apically and centripetally while remaining attached to the basal lamina. This process appears to be evolutionary conserved and may represent a fundamental morphogenetic mechanism driving the formation of multiple ectodermal organs such as a tooth, hair follicle, mammary gland, and sweat glands (Panousopoulou and Green, 2016). Subsequently, mesenchymal cells are attracted to underneath the early dental epithelium, which results in their physical compaction (Mammoto et al., 2011). Such mesenchymal cell condensation in turn triggers the induction of odontogenic expression programs and cell fate specification.

\section{ESTABLISHING THE FACIAL GEOMETRY: THE MESENCHYMAL CONDENSATIONS}

The first solid geometrical layout of the future facial shape is represented by the chondrocranium, the cartilaginous template of the future skull. The chondrocranium is induced when the ectomesenchyme formed the frontonasal outgrowth. A key step preceding the formation of cartilage is the induction of mesenchymal condensations (Figure 1IIB). These are defined areas of mesenchyme that are compacted due to local rapid cell division (Kaucka et al., 2017, 2018; Giffin et al., 2019), and differentiate into cartilage shortly after their emergence (Figure 1IIC). The spatially defined sources of morphogenetic signals, often represented by secreted ligands with long-range action potential (e.g., WNTs, FGFs, BMPs, and Hedgehogs), are referred to as signaling centers or organizers (Figure 1IIIA; Martinez Arias and Steventon, 2018; La Manno et al., 2020). The known signaling centers involved in craniofacial morphogenesis are located in the emerging nervous system, in the foregut endoderm and in spatially defined areas of the facial ectoderm (Marcucio et al., 2005; Wada et al., 2005; Brito et al., 2006;
Eberhart et al., 2006; Foppiano et al., 2007; Szabo-Rogers et al., 2008, 2009; Gitton et al., 2011; Reid et al., 2011; Bhullar et al., 2015; Kaucka et al., 2018; Crane-Smith et al., 2019). Tissueand/or time-specific ablation of morphogens or their sources, such as Sonic Hedgehog (Shh) or the olfactory placodes, showed that the condensations, and in turn the cartilage, are induced by different signaling centers at distinct time points as independent units, pointing at the composite character of the chondrocranium and the future skull (Figures 1 - IIIB,C; McBratney-Owen et al., 2008; Kaucka et al., 2018). Based on the association of the positions of both the signaling centers and skeletal structures induction points (Fabbri et al., 2017), it has been proposed that the species-specific localization of signaling centers located in the brain may represent a reliable criterion to assess skull bone homology (Teng et al., 2019). The Frontonasal Ectodermal Zone (FEZ) of birds and mammals represents a signaling center in the frontal facial ectoderm secreting $\mathrm{SHH}$ and FGF8, coordinating ectomesenchyme behavior and affecting the size, position, shape, and orientation of mesenchymal condensations (Abzhanov et al., 2007; Foppiano et al., 2007; Hu and Marcucio, 2009; Hu et al., 2015a,b).

Both the position of the signaling centers in the developing head and the expression levels of the inductive signals can be modified by several mechanisms. One of them is represented by the cis-regulatory elements (i.e., enhancers) that alter the levels of gene expression. Deletion of enhancers or changes in their sequence can result in a wide range of facial phenotypes (Attanasio et al., 2013; Kaucka et al., 2018). The sequence variation found in regulatory elements of genes associated with facial shape variability and identified epigenetic modifications controlling the enhancer activity in humans (Claes et al., 2018), show that enhancers represent an exceptionally flexible mechanism allowing facial shape fine-tuning (Kaucka et al., 2018) and may account for one of the mechanisms behind intra- and/or inter-species facial differences. Understanding the basis and regulation of mesenchymal condensation induction is further important for the comprehension and management of human craniofacial syndromes. More than $30 \%$ of all congenital abnormalities are represented by craniofacial malformation, ranging from subtle changes of facial features or symmetry to severe conditions affecting feeding, breathing, or other aspects of survival (Xavier et al., 2016; Abramyan, 2019). Interestingly, human craniofacial syndromes are often associated with disorders affecting the central nervous system or the sensory organs (Marcucio et al., 2011; Twigg and Wilkie, 2015), which further underlines the conserved link between the development of the nervous system and the formation of chondrocranium.

\section{DISCUSSION}

The development and availability of new techniques in the last decade have significantly advanced our understanding of the complexity of craniofacial development and opened new perspectives for future research. Single-cell omics analysis can be applied to uncover the gene regulatory networks driving the transitions from mesenchyme to cartilage or to reveal the 
enhancer-driven control of gene expression levels in different cellular populations. This approach, in combination with genetic tracing and live imaging, can further dissect the interactions between various cell or tissue types in detail and resolve, among others, the still enigmatic processes of placode specification and individualization. The precise spatiotemporal mapping of the signaling centers in the developing embryos of various model organisms and exploring their genomic regulation will advance our understanding of both the intra- and interspecies facial variability and the genetic basis of facial features heritability. Additionally, such investigation will allow us to better comprehend the nature of rare craniofacial pathologies.

\section{REFERENCES}

Abramyan, J. (2019). Hedgehog signaling and embryonic craniofacial disorders. J. Dev. Biol. 7:9. doi: 10.3390/jdb7020009

Abzhanov, A., Cordero, D. R., Sen, J., Tabin, C. J., and Helms, J. A. (2007). Cross-regulatory interactions between Fgf8 and Shh in the avian frontonasal prominence. Congenit. Anom. 47, 136-148. doi: 10.1111/j.1741-4520.2007. 00162.x

Adhikari, K., Fuentes-Guajardo, M., Quinto-Sánchez, M., Mendoza-Revilla, J., Camilo Chacón-Duque, J., Acuña-Alonzo, V., et al. (2016). A genome-wide association scan implicates DCHS2, RUNX2, GLI3, PAX1 and EDAR in human facial variation. Nat. Commun. 7:11616. doi: 10.1038/ncomms11616

Attanasio, C., Nord, A. S., Zhu, Y., Blow, M. J., Li, Z., Liberton, D. K., et al. (2013). Fine tuning of craniofacial morphology by distant-acting enhancers. Science 342:1241006. doi: 10.1126/science.1241006

Baggiolini, A., Varum, S., Mateos, J. M., Bettosini, D., John, N., Bonalli, M., et al. (2015). Premigratory and migratory neural crest cells are multipotent in vivo. Cell Stem Cell 16, 314-322. doi: 10.1016/j.stem.2015.02.017

Barriga, E. H., Franze, K., Charras, G., and Mayor, R. (2018). Tissue stiffening coordinates morphogenesis by triggering collective cell migration in vivo. Nature 554, 523-527. doi: 10.1038/nature25742

Basch, M. L., Bronner-Fraser, M. E., and García-Castro, M. I. (2006). Specification of the neural crest occurs during gastrulation and requires Pax7. Nature 441, 218-222. doi: 10.1038/nature04684

Bhattacharya, D., Rothstein, M., Azambuja, A. P., and Simoes-Costa, M. (2018). Control of neural crest multipotency by wnt signaling and the Lin28/let-7 axis. Elife 7:e40556. doi: 10.7554/eLife.40556

Bhullar, B.-A. S., Morris, Z. S., Sefton, E. M., Tok, A., Tokita, M., Namkoong, B., et al. (2015). A molecular mechanism for the origin of a key evolutionary innovation, the bird beak and palate, revealed by an integrative approach to major transitions in vertebrate history. Evolution 69, 1665-1677. doi: 10.1111/ evo. 12684

Bouchard, M., De Caprona, D., Busslinger, M., Xu, P., and Fritzsch, B. (2010). Pax2 and Pax 8 cooperate in mouse inner ear morphogenesis and innervation. BMC Dev. Biol. 10:89. doi: 10.1186/1471-213X-10-89

Breau, M. A., Bonnet, I., Stoufflet, J., Xie, J., De Castro, S., and SchneiderMaunoury, S. (2017). Extrinsic mechanical forces mediate retrograde axon extension in a developing neuronal circuit. Nat. Commun. 8:282. doi: 10.1038/ s41467-017-00283-283

Brito, J. M., Teillet, M.-A., and Le Douarin, N. M. (2006). An early role for sonic hedgehog from foregut endoderm in jaw development: ensuring neural crest cell survival. Proc. Natl. Acad. Sci. U.S.A. 103, 11607-11612. doi: 10.1073/pnas. 0604751103

Brock, L. J., Economou, A. D., Cobourne, M. T., and Green, J. B. A. (2016). Mapping cellular processes in the mesenchyme during palatal development in the absence of Tbxl reveals complex proliferation changes and perturbed cell packing and polarity. J. Anat. 228, 464-473. doi: 10.1111/joa. 12425

Bronner, M. E., and LeDouarin, N. M. (2012). Development and evolution of the neural crest: an overview. Dev. Biol. 366, 2-9. doi: 10.1016/j.ydbio.2011. 12.042
Further research of the conserved developmental link between the formation of the nervous system and the skull may identify new therapeutic targets to reduce the impact of severe congenital syndromes manifested with craniofacial deformities or offer new strategies to enhance cartilage regeneration in adulthood.

\section{AUTHOR CONTRIBUTIONS}

$\mathrm{AM}-\mathrm{R}$ and $\mathrm{MK}$ wrote the manuscript and designed the figure. Both authors contributed to the article and approved the submitted version.

Claes, P., Roosenboom, J., White, J. D., Swigut, T., Sero, D., Li, J., et al. (2018) Genome-wide mapping of global-to-local genetic effects on human facial shape. Nat. Genet. 50, 414-423. doi: 10.1038/s41588-018-0057-4

Cole, J. B., Manyama, M., Kimwaga, E., Mathayo, J., Larson, J. R., Liberton, D. K., et al. (2016). genomewide association study of african children identifies association of SCHIP1 and PDE8A with facial size and shape. PLoS Genet. 12:e1006174. doi: 10.1371/journal.pgen.1006174

Crane-Smith, Z., Schoenebeck, J., Graham, K., Devenney, P., Rose, L., Ditzell, M., et al. (2019). A highly conserved Shh enhancer coordinates hypothalamic and craniofacial development. bioRxiv [Preprint]. doi: 10.1101/794198

Cvekl, A., and Ashery-Padan, R. (2014). The cellular and molecular mechanisms of vertebrate lens development. Development 141, 4432-4447. doi: 10.1242/dev. 107953

David, R., Luu, O., Damm, E. W., Wen, J. W. H., Nagel, M., and Winklbauer, R. (2014). Tissue cohesion and the mechanics of cell rearrangement. Development $141,3672-3682$.

Eberhart, J. K., Swartz, M. E., Crump, J. G., and Kimmel, C. B. (2006). Early Hedgehog signaling from neural to oral epithelium organizes anterior craniofacial development. Development 133, 1069-1077. doi: 10.1242/dev. 02281

Fabbri, M., Mongiardino Koch, N., Pritchard, A. C., Hanson, M., Hoffman, E., Bever, G. S., et al. (2017). The skull roof tracks the brain during the evolution and development of reptiles including birds. Nat. Ecol. Evol. 1, 1543-1550. doi: 10.1038/s41559-017-0288-2

Foppiano, S., Hu, D., and Marcucio, R. S. (2007). Signaling by bone morphogenetic proteins directs formation of an ectodermal signaling center that regulates craniofacial development. Dev. Biol. 312, 103-114. doi: 10.1016/j.ydbio.2007. 09.016

Giffin, J. L., Gaitor, D., and Franz-Odendaal, T. A. (2019). The forgotten skeletogenic condensations: a comparison of early skeletal development amongst vertebrates. J. Dev. Biol. 7:4. doi: 10.3390/JDB7010004

Gitton, Y., Benouaiche, L., Vincent, C., Heude, E., Soulika, M., Bouhali, K., et al. (2011). Dlx5 and Dlx6 expression in the anterior neural fold is essential for patterning the dorsal nasal capsule. Development 138, 897-903. doi: 10.1242/ dev.057505

$\mathrm{Hu}$, D., and Marcucio, R. S. (2009). Unique organization of the frontonasal ectodermal zone in birds and mammals. Dev. Biol. 325, 200-210. doi: 10.1016/ j.ydbio.2008.10.026

Hu, D., Young, N. M., Li, X., Xu, Y., Hallgrimsson, R. S., and Marcucio, R. S. (2015a). A dynamic shh expression pattern, regulated by SHH and BMP signaling, coordinates fusion of primordia in the amniote face. Development $142,567-574$.

Hu, D., Young, N. M., Xu, Q., Jamniczky, R. M., Green, R. M., Mio, R. S., et al. (2015b). Signals from the brain induce variation in avian facial shape. Dev. Dyn. 244, 1133-1143.

Huang, J., Rajagopal, R., Liu, Y., Dattilo, L. K., Shaham, O., Ashery-Padan, R., et al. (2011). The mechanism of lens placode formation: a case of matrix-mediated morphogenesis. Dev. Biol. 355, 32-42. doi: 10.1016/j.ydbio.2011.04.008

Kaucka, M., Ivashkin, E., Gyllborg, D., Zikmund, T., Tesarova, M., Kaiser, J., et al. (2016). Analysis of neural crest-derived clones reveals novel aspects of facial development. Sci. Adv. 2, 11-16. doi: 10.1126/sciadv.1600060 
Kaucka, M., Petersen, J., Tesarova, M., Szarowska, B., Kastriti, M. E., Xie, M., et al. (2018). Signals from the brain and olfactory epithelium control shaping of the mammalian nasal capsule cartilage. Elife 7:e34465.

Kaucka, M., Zikmund, T., Tesarova, M., Gyllborg, D., Hellander, A., Jaros, J., et al. (2017). Oriented clonal cell dynamics enables accurate growth and shaping of vertebrate cartilage. Elife 6, e25902. doi: 10.7554/eLife.25902

Kawasaki, K., and Richtsmeier, J. T. (2017). "Association of the chondrocranium and dermatocranium in early skull formation," in Building Bones: Bone Formation and Development in Anthropology, eds C. Percival and J. Richtsmeier (Cambridge: Cambridge University Press), doi: 10.1017/9781316388907.004

La Manno, G., Soldatov, R., Zeisel, A., Braun, E., Hochgerner, H., Petukhov, V., et al. (2018). RNA velocity of single cells. Nature 560, 494-498. doi: 10.1038/ s41586-018-0414-6

Ladher, R. K., O’Neill, P., and Begbie, J. (2010). From shared lineage to distinct functions: the development of the inner ear and epibranchial placodes. Development 137, 1777-1785. doi: 10.1242/dev.040055

Le Pabic, P., Ng, C., and Schilling, T. F. (2014). Fat-dachsous signaling coordinates cartilage differentiation and polarity during craniofacial development. PLoS Genet. 10:1004726. doi: 10.1371/journal.pgen.1004726

Li, Y., Vieceli, F. M., Gonzalez, W. G., Li, A., Tang, W., Lois, C., et al. (2019). In vivo quantitative imaging provides insights into trunk neural crest migration. Cell Rep. 26, 1489.e3-1500.e3. doi: 10.1016/j.celrep.2019.01.039

Lignell, A., Kerosuo, L., Streichan, S. J., Cai, L., and Bronner, M. E. (2017). Identification of a neural crest stem cell niche by Spatial Genomic Analysis. Nat. Commun. 8:1830. doi: 10.1038/s41467-017-01561-w

Liu, F., van der Lijn, F., Schurmann, C., Zhu, G., Chakravarty, M. M., Hysi, P. G., et al. (2012). A genome-wide association study identifies five loci influencing facial morphology in europeans. PLoS Genet. 8:1002932. doi: 10.1371/journal. pgen. 1002932

Mammoto, T., Mammoto, A., Torisawa, Y., Tat, T., Gibbs, A., Derda, R., et al. (2011). Mechanochemical control of mesenchymal condensation and embryonic tooth organ formation. Dev. Cell 21, 758-769. doi: 10.1016/j.devcel. 2011.07.006

La Manno, G., Siletti, K., Furlan, A., Gyllborg, D., Vinsland, E., et al. (2020). Molecular architecture of the developing mouse brain. bioRxiv [Preprint]. doi: 10.1101/2020.07.02.184051

Marcucio, R. S., Cordero, D. R., Hu, D., and Helms, J. A. (2005). Molecular interactions coordinating the development of the forebrain and face. Dev. Biol. 284, 48-61. doi: 10.1016/J.YDBIO.2005.04.030

Marcucio, R. S., Young, N. M., Hu, D., and Hallgrimsson, B. (2011). Mechanisms that underlie co-variation of the brain and face. Genesis 49, 177-189. doi: 10.1002/dvg.20710

Martik, M. L., Gandhi, S., Uy, B. R., Gillis, J. A., Green, S. A., Simoes-Costa, M., et al. (2019). Evolution of the new head by gradual acquisition of neural crest regulatory circuits. Nature 574, 675-678. doi: 10.1038/s41586-019-1691-4

Martinez Arias, A., and Steventon, B. (2018). On the nature and function of organizers. Developemt 145:dev159525. doi: 10.1242/dev.159525

McBratney-Owen, B., Iseki, S., Bamforth, S. D., Olsen, B. R., and Morriss-Kay, G. M. (2008). Development and tissue origins of the mammalian cranial base. Dev. Biol. 322, 121-132. doi: 10.1016/j.ydbio.2008.07.016

Méhes, E., and Vicsek, T. (2014). Collective motion of cells: from experiments to models. Integr. Biol. 6, 831-854.

Minoux, M., Holwerda, S., Vitobello, A., Kitazawa, T., Kohler, H., Stadler, M. B., et al. (2017). Gene bivalency at Polycomb domains regulates cranial neural crest positional identity. Science 355:eaal2913. doi: 10.1126/science.aal2913

Minoux, M., and Rijli, F. M. (2010). Molecular mechanisms of cranial neural crest cell migration and patterning in craniofacial development. Development 137, 2605-2621. doi: 10.1242/DEV.040048

Panousopoulou, E., and Green, J. B. A. (2016). Invagination of ectodermal placodes is driven by cell intercalation-mediated contraction of the suprabasal tissue canopy. PLoS Biol. 14:e1002405. doi: 10.1371/journal.pbio.1002405

Pla, P., and Monsoro-Burq, A. H. (2018). The neural border: induction, specification and maturation of the territory that generates neural crest cells. Dev. Biol. 444, S36-S46. doi: 10.1016/j.ydbio.2018.05.018

Prasad, M. S., Uribe-Querol, E., Marquez, J., Vadasz, S., Yardley, N., Shelar, P. B., et al. (2020). Blastula stage specification of avian neural crest. Dev. Biol. 458, 64-74. doi: 10.1016/j.ydbio.2019.10.007
Rao, A., and LaBonne, C. (2018). Histone deacetylase activity has an essential role in establishing and maintaining the vertebrate neural crest. Developmet 145:dev163386. doi: 10.1242/dev.163386

Reid, B. S., Yang, H., Melvin, V. S., Taketo, M. M., and Williams, T. (2011). Ectodermal Wnt/ $\beta$-catenin signaling shapes the mouse face. Dev. Biol. 349, 261-299. doi: 10.1016/J.YDBIO.2010.11.012

Richardson, J., Gauert, A., Briones Montecinos, L., Fanlo, L., Alhashem, Z. M., Assar, R., et al. (2016). Leader cells define directionality of trunk, but not cranial, neural crest cell migration. Cell Rep. 15, 2076-2088. doi: 10.1016/j.celrep.2016. 04.067

Riddiford, N., and Schlosser, G. (2016). Dissecting the pre-placodal transcriptome to reveal presumptive direct targets of Six 1 and Eyal in cranial placodes. Elife 5:e17666. doi: 10.7554/eLife.17666

Roellig, D., Tan-Cabugao, J., Esaian, S., and Bronner, M. E. (2017). Dynamic transcriptional signature and cell fate analysis reveals plasticity of individual neural plate border cells. Elife 6:e21620. doi: 10.7554/eLife. 21620

Rothstein, M., Bhattacharya, D., and Simoes-Costa, M. (2018). The molecular basis of neural crest axial identity. Dev. Biol. 444, S170-S180. doi: 10.1016/j.ydbio. 2018.07.026

Saint-Jeannet, J. P., and Moody, S. A. (2014). Establishing the pre-placodal region and breaking it into placodes with distinct identities. Dev. Biol. 389, 13-27. doi: 10.1016/j.ydbio.2014.02.011

Sato, S., Ikeda, K., Shioi, G., Ochi, H., Ogino, H., Yajima, H., et al. (2010). Conserved expression of mouse Sixl in the pre-placodal region (PPR) and identification of an enhancer for the rostral PPR. Dev. Biol. 344, 158-171. doi: 10.1016/j.ydbio. 2010.04.029

Scarpa, E., Szabó, A., Bibonne, A., Theveneau, E., Parsons, M., and Mayor, R. (2015). Cadherin switch during EMT in neural crest cells leads to contact inhibition of locomotion via repolarization of forces. Dev. Cell 34, 421-434. doi: 10.1016/j.devcel.2015.06.012

Shellard, A., and Mayor, R. (2019). Integrating chemical and mechanical signals in neural crest cell migration. Curr. Opin. Genet. Dev. 57, 16-24. doi: 10.1016/j. gde.2019.06.004

Soldatov, R., Kaucka, M., Kastriti, M. E., Petersen, J., Chontorotzea, T., Englmaier, L., et al. (2019). Spatiotemporal structure of cell fate decisions in murine neural crest. Science 364:eaas9536. doi: 10.1126/science.aas9536

Steventon, B., Mayor, R., and Streit, A. (2016). Directional cell movements downstream of Gbx2 and Otx2 control the assembly of sensory placodes. Biol. Open 5, 1620-1624. doi: 10.1242/bio.020966

Szabó, A., Theveneau, E., Turan, M., and Mayor, R. (2019). Neural crest streaming as an emergent property of tissue interactions during morphogenesis. PLoS Comput. Biol. 15:e1007002. doi: 10.1371/journal.pcbi.100 7002

Szabo-Rogers, H. L., Geetha-Loganathan, P., Nimmagadda, S., Fu, K. K., and Richman, J. M. (2008). FGF signals from the nasal pit are necessary for normal facial morphogenesis. Dev. Biol. 318, 289-302. doi: 10.1016/J.YDBIO.2008.03. 027

Szabo-Rogers, H. L., Geetha-Loganathan, P., Whiting, C. J., Nimmagadda, S., Fu, K., and Richman, J. M. (2009). Novel skeletogenic patterning roles for the olfactory pit. Development 136, 219-229. doi: 10.1242/dev.02 3978

Tao, H., Zhu, M., Lau, K., Whitley, O. K. W., Samani, M., Xiao, X., et al. (2019). Oscillatory cortical forces promote three dimensional cell intercalations that shape the murine mandibular arch. Nat. Commun. 10:1703. doi: 10.1038/ s41467-019-09540-z

Teng, C. S., Cavin, L., Maxson, R. E., Sánchez-Villagra, M. R., and Crump, J. G. (2019). Resolving homology in the face of shifting germ layer origins: lessons from a major skull vault boundary. Elife 8:e52814. doi: 10.7554/eLife. 52814

Theveneau, E., and Mayor, R. (2012). Neural crest delamination and migration: from epithelium-to-mesenchyme transition to collective cell migration. Dev. Biol. 366, 34-54. doi: 10.1016/j.ydbio.2011.12.041

Theveneau, E., Steventon, B., Scarpa, E., Garcia, S., Trepat, X., Streit, A., et al. (2013). Chase-and-run between adjacent cell populations promotes directional collective migration. Nat. Cell Biol. 15, 763-772. doi: 10.1038/ncb 2772 
Twigg, S. R. F., and Wilkie, A. O. M. (2015). A genetic-pathophysiological framework for craniosynostosis. Am. J. Hum. Genet. 97, 359-377. doi: 10.1016/ j.ajhg.2015.07.006

Wada, N., Javidan, Y., Nelson, S., Carney, T. J., Kelsh, R. N., and Schilling, T. F. (2005). Hedgehog signaling is required for cranial neural crest morphogenesis and chondrogenesis at the midline in the zebrafish skull. Development 132, 3977-3988. doi: 10.1242/dev.01943

Williams, R. M., Candido-Ferreira, I., Repapi, E., Gavriouchkina, D., Senanayake, U., Ling, I. T. C., et al. (2019). Reconstruction of the global neural crest gene regulatory network in vivo. Dev. Cell 51, 255.e7-276.e7. doi: 10.1016/j.devcel. 2019.10.003

Xavier, G. M., Seppala, M., Barrell, W., Birjandi, A. A., Geoghegan, F., and Cobourne, M. T. (2016). Hedgehog receptor function during craniofacial development. Dev. Biol. 415, 198-215. doi: 10.1016/j.ydbio.2016.02.009
Xiong, Z., Dankova, G., Howe, L. J., Lee, M. K., Hysi, P. G., De Jong, M. A., et al. (2019). Novel genetic loci affecting facial shape variation in humans. Elife 8:e49898. doi: 10.7554/eLife.49898

Conflict of Interest: The authors declare that the research was conducted in the absence of any commercial or financial relationships that could be construed as a potential conflict of interest.

Copyright (c) 2020 Murillo-Rincón and Kaucka. This is an open-access article distributed under the terms of the Creative Commons Attribution License (CC BY). The use, distribution or reproduction in other forums is permitted, provided the original author(s) and the copyright owner(s) are credited and that the original publication in this journal is cited, in accordance with accepted academic practice. No use, distribution or reproduction is permitted which does not comply with these terms. 